\title{
HOW ARE END-OF-LIFE STRATEGIES ADOPTED IN PRODUCT-SERVICE SYSTEMS? A SYSTEMATIC REVIEW OF GENERAL CASES AND CASES OF MEDICAL DEVICES INDUSTRY
}

\author{
Damha, Leticcia Giovana; Trevisan, Adriana Hofmann; Costa, Daniel Guzzo; Costa, Janaina \\ Mascarenhas Hornos
}

University of São Paulo

\begin{abstract}
Little study has been done on the adoption of End-of-Life (EoL) strategies on the medical devices industry, despite the reasons why it is an important area of study for the implementation of circularity. The rates of waste in the medical field are alarming and tend to grow. Though presenting a wide potential for EoL strategies implementation, the medical field is also inherently challenging, considering the rigid regulations and product's risk to patients life. This paper analyses 17 Product-Service System case studies identified in the literature. Eleven of them are from various fields of industry, whereas the other six are applied to the medical devices industry. The adoption of EoL strategies - namely repair, reconditioning, remanufacture and recycling - is analysed in each case and compared for the two categories of cases. This adoption is related to the sources of value creation in Circular Economy, to the PSS typology and, at last, special EoL treatment for medical devices is discussed.
\end{abstract}

Keywords: Circular economy, Product-Service Systems (PSS), Sustainability, Medical Devices, Endof-Life

Contact:

Damha, Leticcia Giovana

University of São Paulo

Industrial Engineering Department

Brazil

leticcia.damha@usp.br

Cite this article: Damha, L.G., Trevisan, A.H., Costa, D.G., Costa, J.M.H. (2019) 'How are End-of-Life Strategies

Adopted in Product-Service Systems? A Systematic Review of General Cases and Cases of Medical Devices Industry', in Proceedings of the 22nd International Conference on Engineering Design (ICED19), Delft, The Netherlands, 5-8 August 2019. DOI:10.1017/dsi.2019.313 


\section{INTRODUCTION}

Product-Service Systems (PSS) combine products, services and a network of partners in order to deliver a solution demanded by the final customer (Tukker and Tischner, 2006). It involves dematerialization and the absence of ownership transference between the manufacturer and final consumer, which encourages the PSS provider to enhance the utilization and reliability of the asset (Baines et al., 2007). This leads to a potential extension of its use-life and resource- and costefficiency, providing cycles of use of the whole asset and/or its components (Tukker, 2015).

PSS is intimately linked to the concept of Circular Economy (CE), which is guided by the desire to keep materials, products and components at their highest value and functionality at all times (Ellen MacArthur Foundation, 2015). Pieroni et al. (2018), describes some nordic examples of businesses that promote CE through PSS, such as Martela, a furniture company that offers rental and leasing and, in the EoL, receive back the furniture to be reused as a whole after reconditioning, or as components that will integrate new assemblies, or, as a last option, send separated materials to recycling. The CE seeks to decouple economic development from finite resource consumption (Liu et al., 2009) and, thus, reduce environmental pressure (Tukker, 2015).

One of the core principles of CE consists on the optimization of resource yields, which can be explored through the circulation of products, components and materials, in order to maintain them at the highest utility and contributing to the economy (Blomsma and Brennan, 2017). Ellen MacArthur Foundation (2015) presents the sources of value creation in a CE namely inner circle, circling longer and cascade use, whose power resides in circling products and/or materials to guarantee that they keep the most of their value for the longest period.

The inclusion of End-of-Life (EoL) strategies in the development of products raises the possibility of slowing and closing resource loopings. This means extension and/or intensification of the use period and, after that, closing the looping between post-use and production of new items (Bocken et al., 2016), avoiding waste disposal. Therefore, EoL strategies are closely linked to the feasibility of the $\mathrm{CE}$, so that they should be explored in a diverse range of economic sectors. One of these sectors is the medical devices industry that presents substantial potential for the implementation of these strategies jointly with a shift in the mindset, from linear to circular thinking (Kane et al., 2017).

The medical field is characterised by strict regulation on equipment safety, besides the fact that many of these equipment can be harmful to patient's life (Kane et al., 2017), due to failure either in the sterilization process or in the functionality of the asset. However, stronger than the aforementioned challenges for EoL strategies implementation, are the reasons why circular solutions should be adopted in this area. Minoglou et al. (2017) emphasize how alarming the amount of waste produced by healthcare worldwide is, especially considering that this area is growing rapidly due to the increase of ageing populations, emerging markets and specific diseases (Landolfi et al., 2014).

Furthermore, Yip et al. (2015) and Fargnoli et al. (2018) underline the lack of studies regarding the implementation of PSS in the medical devices area and remarked this subject as an important field for scientific investigation. Accordingly, the main research question that this paper responds is: how do the general and medical PSS cases available in literature address the implementation of EoL strategies and how do they differ? The remainder of the paper is structured as follows: Section 2 is divided into two sub-sections, containing the Literature Review on PSS and Circular Economy and End-of-Life Strategies; Section 3 describes the Methodology used to gather and analyze data; Section 4 discusses the results obtained from the analysis; and, finally, in the last section conclusions are drawn.

\section{LITERATURE REVIEW}

\subsection{PSS and circular Economy}

Product Service Systems consist of a marketable set of products and services designed and combined so that they are jointly capable of fulfilling the final customer needs (Goedkoop 1999). Tukker (2004) categorized possible applications of this mix of physical product and services in three possible classes: i) Product-oriented: the business model is still headed towards the sale of physical products, even though the PSS provider offers additional services linked to the physical asset; ii) Use-oriented: an important switch is recognized compared to traditional business models, since it is not focused on selling products, although the product still plays the central role of the solution offered, and the PSS 
provider is the asset's owner during the whole use phase and iii) Result-oriented: here, the PSS provider agrees with the client on a specific result and the provider should guarantee this result through a solution that involves a set of products and services.

Since PSS gradually advances towards selling use rather than a product itself, the provider comes across a completely new scenario, whereby retaining asset ownership means a chance to enhance utilization, reliability, design and protection of the product (Baines et al., 2007). This brings to light the core environmental potential associated with PSS: firms will acknowledge an incentive to prolong the service life of products through reusing the whole asset or components, in order to ensure that they are used as intensively and as long as possible, leading ultimately to a minimization of material flows in the economy combined with user satisfaction enhancement (Tukker, 2015).

Mont et al. (2006) state that, in order to contribute to sustainable development, the PSS provider should make effort to lengthen product longevity through maintenance and upgrading until reaching the EoL phase, when the product should be taken back and recovered through repair, reconditioning, remanufacturing and recycling, instead of being sold to a third party. Thus, Tukker (2015) affirms that PSS business model is one of the most important approaches to make the CE feasible. It denies takemake-use-dispose models and, in order to reach the CE, shifts businesses' profiting sources from selling products to enhancing the flow of materials and products over time (Bocken et al., 2016).

Ellen MacArthur Foundation (2015) introduces four different ways of looping products and materials aiming at enabling the CE, which are: i) Inner Circles: values strategies that maintain the most of the product's value, such as repairing and maintaining, since it preserves the integrity, complexity and embedded energy of the asset, once it is not possible to recover the product as a whole, the reuse of components should be prioritized; ii) Circling Longer: aims at maximizing the number of consecutive use cycles of a product and/or the duration of each cycle, which ultimately lengthen the use life of the product; iii) Cascade Use: proposes diverse reuse strategies across the value chain, namely secondhand markets and recycling; and iv) Pure Inputs: its power lies on the use of uncontaminated resources and, therefore, the increase of efficiency in terms of collection and redistribution of material streams, whilst extending material productivity. Pure Inputs, i.e initiatives which narrow the flow of resources, are mainly associated to resource use on the production process (Bocken, et al., 2016), and thus can be best explored by in the phase of Beginning-of-Life, whereas the other three aforementioned are connected to Middle-of-Life and End-of-Life. Hence, this paper takes into consideration Inner Circles, Circling Longer and Cascade Use as ways of looping resources that depend of or are connected in certain ways to the implementation of EoL strategies.

\subsection{End-of-life strategies}

Hollander et al. (2017) present the difference between use cycle and lifetime of a product: while lifetime is the period from the product release until it becomes obsolete beyond recovery at product level, an use cycle is characterized as the period between release/recovery, when the product is ready to be used, and obsolescence, which can or cannot be reverted by a recovery process. Thus, a product can have more than one use cycle, but only one lifetime (Hollander et al., 2017).

Obsolescence means that a product is no longer considered useful and lost part of its perceived value, which can be triggered by different reasons (Hollander et al., 2017). These reasons were categorized in various classes by different authors and Burns (2016) discerns four main reasons: i) aesthetic: product is considered outmoded; ii) social: product is considered outlawed; iii) technological: new technology that performs better has been developed; and iv) economic: occurs when it is cheaper to buy a new product than to recover the one that is currently being used.

There are different ways of dealing with obsolescence and two of them are postponing, through upgrading, for example, and reversing, what can be made through repairing, reconditioning (or refurbishment) and remanufacturing (Hollander et al., 2017). When it is not possible to reverse obsolescence at product level, the EoL strategy of recycling can be adopted, since it guarantees obsolescence reversement at material level, permanently compromising the product integrity.

Hence, the literature presents 5 main EoL strategies (besides the usual disposal) that deal with obsolescence and operate towards the CE, either in product or material levels:

Repair: consists in the correction of specific faults that compromise the functionality of the product (Hollander et al., 2017). The final result has inferior quality compared to a new product or to products that have been modified through other EoL strategies (King et al., 2006). 
Upgrade: process that enhances the functional capabilities and/or cosmetic condition. It is usually done on products that still work properly, however, can be updated or new functionalities can be added. This strategy prolongs both the use cycle and the product lifetime. (Hollander et al., 2017).

Reconditioning/Refurbishment: major components of the product are rebuilt or replaced if they are identified as parts that have failed or are on the point of failure, even though it has not been noticed and reported by the user (Hollander et al., 2017). After reconditioning, the product is usually not expected to recover its original condition (King et al., 2006).

Remanufacture: the product is dismantled and, after appropriate cleaning and inspection, the parts suitable for remanufacturing go through the machining processes in order to recover the specification of a new one (Sundin and Lee, 2012). Once the components were remanufactured, they are recombined to build a new product using components originated from different units of the product and using as few new components as possible (Hollander et al., 2017).. It is important to notice that between the phases of inspection and the actual remanufacture, the costs are estimated and quoted for each product, in order to determine the best rectification strategy (King et al., 2006).

Recycling: this process differs from the aforementioned, once the strategy recovers the materials and not the product (Hollander et al., 2017). The process begins after the disposal of an asset, when the materials are collected, sorted and processed in a way that it may be used in the production of new products (Kane et al., 2017). Recycling is a very popular EoL strategy and it certainly reduces virgin material consumption. However, it is important to emphasize that, after recycling, the material requires additional energy to be manufactured into a new product, whereas repairing, reconditioning, remanufacturing and upgrading demand less energy (King et al., 2006).

Aiming the adoption of the appropriate EoL option considering the environmental impact and the value retained in resources, the EoL hierarchy created by Sundin and Lee (2012) prioritises options as follows: reuse, repair, reconditioning, remanufacture and recycling. Such End-of-Life hierarchy corresponds to the Inertia Principle of Walter Stahel (Stahel, 2010, p.195).

\section{RESEARCH METHODS}

A Literature Review enabled deepening the knowledge concerning PSS concept and practices, its relation to Circular Economy and further information about EoL strategies and the advantages and disadvantages related to the adoption of each one. A Systematic Review approach aimed at finding PSS case studies available in the literature, which was focused in two subjects: cases of all market fields and cases of the medical field specifically. The systematic review approach was elected due to its increased methodological rigour and, consequently, reliable resulting knowledge from a range of previous studies (Tranfield et al., 2003). Firstly, a sustainable PSS case studies database was accessed in order to obtain cases belonging to any market field. With the intent of providing data for posterior studies, this database was created by the research group of Integrated Engineering of the University of São Paulo. The case studies database originated from a string (see Figure 1) applied to Scopus and Web-of-Science and is continually updated. In order to select only the relevant cases for this study, a filter was applied taking into consideration whether the cases presented EoL strategies. This process resulted 13 case studies, identified in 12 scientific papers. However, one of the cases was about an application in the medical field and was, thus, considered in the industry-specific part of the analysis, since it was also found in the systematic review of the medical sector. It is important to emphasize that the unit of analysis is the case study and one paper can present more than one case to be examined.

Secondly, a systematic review string was formulated aiming at obtaining PSS cases applied to the medical field (see Figure 1). The string was used to search the fields of title, abstract and keywords in the following databases: Scopus and Web of Science; only scientific articles and book chapters were considered. After removing all duplicates, three filters were applied (detailed in Figure 1), considering the abstract and the description of each case. The 2 scientific papers and 1 book chapter that remained after the application of the filters contributed with 6 case studies for posterior analysis. 


\begin{tabular}{|c|c|c|c|}
\hline \multicolumn{4}{|c|}{ Systematic Review Approach } \\
\hline All market fields & \multicolumn{3}{|c|}{ Medical field } \\
\hline $\begin{array}{l}\text { String: (case OR "real case" OR "real application" OR "case } \\
\text { application" OR "case study" OR "case research") AND } \\
\text { TITLE-ABSTR-KEY(PSS OR "Product-service system*") AND }\end{array}$ & \multicolumn{3}{|c|}{$\begin{array}{c}\text { String: ( "Product-service system" OR "servitization" OR } \\
\text { "Integrated Product Support Services" OR "Integrated Product } \\
\text { and Service" ) AND ( "medical" OR "health" ) }\end{array}$} \\
\hline $\begin{array}{c}\text { ("environmental aspects" OR "environmental impacts" OR } \\
\text { "environmental benefits" OR "social aspects" OR "social impacts" } \\
\text { OR "social benefits" OR "economic aspects" OR "economic } \\
\text { impacts" OR "economic benefits") }\end{array}$ & \multirow{2}{*}{$\begin{array}{l}\text { 1st filter (abstract): } \\
\text { mention a case } \\
\text { study in the } \\
\text { medical field, } \\
\text { mention PSS }\end{array}$} & \multirow{2}{*}{$\begin{array}{l}\text { 2nd filter (article): } \\
\text { sufficiently detailed } \\
\text { case study } \\
\text { containing physical } \\
\text { asset }\end{array}$} & \multirow{2}{*}{$\begin{array}{l}\text { 3rd filter } \\
\text { (article): } \\
\text { mention the } \\
\text { adoption of } \\
\text { EoL strategies }\end{array}$} \\
\hline Filter: case study mention the adoption of EOL strategies & & & \\
\hline 11 case studies from 10 papers & \multicolumn{3}{|c|}{6 case studies from 3 papers } \\
\hline
\end{tabular}

Figure 1. Details about the systematic review approach

The strings used for both systematic reviews are specified in Figure 1, jointly with the numbers of publications returned and of case studies identified. The meticulous read of the papers was assisted by MAXQDA $^{\circledR}$, a qualitative analysis software that allows the researcher to organize and catalogue information using a wide range of tools. Then, a record was created for each case study, in order to retain the most important information and facilitate further analysis. These records were read by two other authors, what was carefully made in order to validate information and avoid any biases.

Table 1. Data about the case studies

\begin{tabular}{|c|c|c|c|c|c|c|c|c|c|}
\hline \multirow{2}{*}{$\stackrel{0}{0}$} & \multicolumn{3}{|c|}{ PSS case studies } & \multirow{2}{*}{ 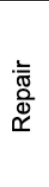 } & \multirow{2}{*}{ 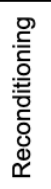 } & \multirow{2}{*}{ 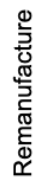 } & \multirow{2}{*}{ 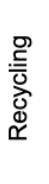 } & \multirow{2}{*}{$\begin{array}{l}\frac{0}{0} \\
\frac{\pi}{0} \\
\frac{0}{2}\end{array}$} & \multirow{2}{*}{ 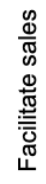 } \\
\hline & Publication & Physical product of the PSS offer & PSS Typology & & & & & & \\
\hline $1 G$ & Allais, R., Gobert, J., 2016 & Small Household Equipment & Use oriented & & & • & • & & • \\
\hline $2 \mathrm{G}$ & Amaya, J. et al., 2014 & Bicycle & Use oriented & • & & & & & \\
\hline $3 G$ & Chun, Y., Lee K., 2017 & Water purifier for home use & Use oriented & • & & & & & \\
\hline $4 \mathrm{G}$ & Lindahl, M. et al., 2014 & Core plugs used by paper mills & Result oriented & & & & • & & \\
\hline $5 G$ & Lindahl, M. et al., 2014 & Soil compactors & Use oriented & • & & • & & & \\
\hline $6 \mathrm{G}$ & Shokohyar, S. et al., 2012 & Notebook & Product oriented & - & & & & & $\mathrm{n} / \mathrm{a}$ \\
\hline $7 G$ & Song W., Sakao, T., 2018 & Lift & Product oriented & • & & & & & $\mathrm{n} / \mathrm{a}$ \\
\hline $8 G$ & $\begin{array}{c}\text { Sousa-Zomer, T., Miguel, P., } \\
2018\end{array}$ & Water purifiers & Result oriented & • & • & & • & • & \\
\hline $9 G$ & Xing, K. et al., 2013 & Hybrid heating system & Use oriented & • & & & & • & \\
\hline $10 G$ & Zhang W. et al., 2018 & Air separation equipment & Use oriented & - & & & • & & \\
\hline $11 \mathrm{G}$ & Sousa-Zomer, T. et al., 2017 & Water filtration system & Use oriented & $\bullet$ & & & • & & \\
\hline $1 \mathrm{MF}$ & Fargnoli, M. et al., 2018 & Hemodialysis equipment & Use oriented & • & • & & & & \\
\hline 2MF & Schröter M., Lay G., 2014 & Appliances for water jet surgery & Use oriented & & & & & & $\cdot$ \\
\hline 3MF & Schröter M., Lay G., 2014 & $\begin{array}{l}\text { X-ray machines, examination systems based } \\
\text { on ultrasound }\end{array}$ & Use oriented & • & • & & & & - \\
\hline 4MF & Schröter M., Lay G., 2014 & Endoscopy incl. peripheral equipment & Use oriented & • & & & & & $\cdot$ \\
\hline $5 \mathrm{MF}$ & Schröter M., Lay G., 2014 & Endoscopy incl. peripheral equipment & Use oriented & • & • & & & & $\cdot$ \\
\hline $6 \mathrm{MF}$ & Adeogun, O. et al., 2010 & Glucometer & Result oriented & & & & & - & \\
\hline
\end{tabular}

\section{RESULTS AND DISCUSSION}

The cases obtained from the systematic literature review are presented in Table 1. These are classified into general cases (expressed by a number and the letter $\mathrm{G}$ ) and medical field cases (number and MF). Besides, there is data about the publication, author and year, the solution provided by the PSS offer, PSS typology according to Tukker (2004), and the EoL strategies adopted in each case. An additional 
strategy, related to the end of PSS contracts, was considered for analysing the cases since it was recurrently applied: Facilitated Sales. Such strategy indicates that the products used in the PSS can be sold after the contract period for a reduced value either for its current customer or in the second-hand market. This option is possible for PSS that are use or result oriented, since the product oriented PSS necessarily involves the sale of the physical product.

It is possible to analyse that, among the medical cases, facilitated sales was frequently mentioned in the papers (4 out of 6), which indicates a tendency of the PSS providers of selling products before they actually reach the EoL phase. Thereafter, the PSS provider cannot be responsible for guaranteeing the most appropriate EoL strategy for the asset any longer, and the opportunity to seek product circularity through PSS might be lost. Case 2MF, introduced by Schröter and Lay, is an example of PSS in which the provider has the unique intention, at the end of the contract period, to have the products acquired by the customer and, thus, is lost the opportunity of recovering the product for new cycles of use or of recycling the materials. This tendency is also clear in case 3MF, whereby the authors emphasize that recovery strategies are only adopted when the product was not bought for a residual value by the user, being the facilitated sale prioritized for the PSS provider.

\subsection{Linking EoL strategies and PSS typology}

Tukker (2004) developed the PSS typology, which enables an analysis relating the three PSS classes to the adoption of EoL strategies. Product oriented PSS is characterized by the sale of a product, to which some services are added. Among the cases studied in this paper, two present product oriented PSS (6G and $7 \mathrm{G}$ ) and none of them belong to the medical field. Cases $6 \mathrm{G}$ and $7 \mathrm{G}$ adopt only repair as EoL strategy. In case 6G, the PSS offer includes repair only during the warranty period of the notebook and in case $7 \mathrm{G}$, repair and also spare parts are provided for the lift during all contract period. It is important to note that product oriented PSS presents some barriers to the adoption of EoL strategies such as reconditioning and remanufacture, since the PSS provider is not the owner of the product in the use and End-of-Life phases.

In use and result oriented PSS, the product belongs to the PSS provider during the use phase in a way that the provider is responsible for the EoL of the assets. Most of the cases analysed are use oriented $(1 \mathrm{G}, 2 \mathrm{G}, 3 \mathrm{G}, 5 \mathrm{G}, 9 \mathrm{G}, 10 \mathrm{G}, 11 \mathrm{G}, 1 \mathrm{MF}, 2 \mathrm{MF}, 3 \mathrm{MF}, 4 \mathrm{MF}$ and $5 \mathrm{MF})$ and there is no clear pattern among these cases that systematizes the EoL adoption. Nevertheless, it is possible to notice that providers of use oriented PSS tend to adopt two or more EoL strategies, that remanufacture was identified only in these cases and that reconditioning was adopted mainly in use oriented cases (except 8G, that is result oriented). Among the three result oriented PSS cases, it is possible to identify the adoption of all the EoL options, except remanufacture. It does not necessarily mean that result oriented PSS presents barriers to the implementation of this strategy specifically.

\subsection{Linking EoL strategies and Circular Economy sources}

\section{Inner Circles}

Ellen MacArthur Foundation (2015) presents Inner Circles as a source of value creation in Circular Economy scenario. This source aims at maintaining the most of the resources and products value throughout the use phase and, when it is not possible to recover the whole product, its components should be reused (Ellen MacArthur Foundation, 2015). Therefore, even though it refers to the use phase, this source is tightly linked to the strategy of repair.

Among the 23 case studies analysed, 14 mentioned that repairing is a strategy adopted by the PSS providers. Most of them utilize this strategy only during the use cycle in order to maintain the product's functionality, and not as a manner of recovering it to enable another cycle of use. In most of the cases, repairing is offered as part of the maintenance service, which is usually included in the PSS provision (cases 2G, 3G, 5G, 7G, 8G, 9G, 10G, 11G, 1MF, 3MF, 4MF and 5MF). When the contract settled agrees on a product oriented PSS, sometimes repairing is possible only during the warranty period, as evidenced by the authors of the case $6 \mathrm{G}$, which hinders the potential to contribute to a $\mathrm{CE}$, especially considering that products tend to break the further they are in a given use cycle.

\section{Circling Longer}

Since this source intends to maximise the number of use cycles and/or the duration of each cycle (Ellen MacArthur Foundation, 2015), it can be enabled by the EoL strategies of reconditioning, remanufacture and upgrade. The three act towards augmenting the number of use cycles, whilst the 
third also extends the period of a cycle. In total, 8 cases present at least one of these three EoL strategies related to circling longer.

Four cases mention the adoption of reconditioning and three of them are from the medical field (1MF, $2 \mathrm{MF}$ and $3 \mathrm{MF})$. The only case that is not from the medical field $(8 \mathrm{G})$ is about water purifiers. The PSS provider has designed a product aiming at extending the product's lifetime and enabling more than one use cycle, so that the only EoL strategy that is not adopted in this case is remanufacturing. In 1MF, the authors present use oriented PSS as a proposal for the hemodialysis equipment and estimate that $35 \%$ of the devices would go under full refurbishment and $60 \%$ under light refurbishment, leaving only $5 \%$ to be disposed of after the 4-year use cycle. Case $2 \mathrm{MF}$ mentions reconditioning as a strategy used to recover products and guarantee a new use cycle as practically new appliances. Case $3 \mathrm{MF}$, on the other hand, states that reconditioning is applied only in cases when the user does not buy the product for a residual value, what implies that facilitated sales are preferred.

Analysing the implementation of remanufacture, it is possible to notice that this is the less frequently adopted EoL strategy among the cases studied in this paper and was not mentioned by any of the medical field cases. One possible reason is the nomenclature used in the medical industry of different regions of the globe. As reported by the Centre for Remanufacturing and Reuse (CRR) of the United Kingdom (UK), in the European Union (EU), a remanufactured medical device must have a better scope than it had originally and, thus, the remanufacturer must reapply for conformity standards; in the USA, on the other hand, remanufacture refers to a process that recovers the original characteristics of the product (CRR, 2018). The term 'refurbishment' is used in the EU to designate the process that recovers the original scope of medical devices (CRR, 2018), so that it includes partially the definitions of reconditioning and remanufacture used in this paper. It is also important to emphasize that the four cases presented by Schröter and Lay (2014) are from german industries and the authors of the other two medical cases are also from the EU, even though they do not specify the nationality of the industries they have studied.

In case $1 \mathrm{G}$, remanufacture is one of the EoL strategies that can be adopted for the product depending on the value recovery potential, and the authors underline that the environmental interest of remanufacture is the lower material consumption compared to manufacturing a new product. Case $5 \mathrm{G}$ shows special attention for remanufacture, since the authors describe an effort of the PSS provider to design products aiming to ease the remanufacturing process and, thus, reduce times and costs.

Upgrade is mentioned in only three of the case studies. Case $8 \mathrm{G}$ remarks that the water purifiers are designed to be upgradable, but the authors provide no further information about the process of upgrading. Case $9 \mathrm{G}$ adopts upgrade in the middle of the high-service contract period, as a differential of the other two possible contract models presented by the PSS provider, however, the paper does not mention what happens to the equipment in the end of the contract duration. Case 6MF also presents upgrade as an advantage for customers during the contract period. The PSS provider ensures that, each time a new model is released, the glucometer returns to the manufacturer to be upgraded and then can continue to be used by the same customer, since this device is designed for individual use due to its contact to patient's blood.

\section{Cascade Use}

Since cascade use refers to expanding reuse across the value chain, not necessarily maintaining the same functionality for products and possibly reusing only the materials (Ellen MacArthur Foundation, 2015), the EoL strategy that fit in this source of value creation is recycling. Recycling is mentioned in six of the cases, but no one of them is about the medical industry, being recycling another EoL strategy that was not adopted by any of the study cases returned by the string. Case $1 \mathrm{G}$ highlights a special attention of the manufacturer for developing products that are designed for disassembly in order to facilitated the recycling process. Case $5 \mathrm{G}$ is very interesting, once all the products are manufactured by a special material that enables, after various use cycles, an easy recycling process made by the manufacturer himself before the recycled material goes through the machining processes to be transformed into new products once again. This cycle occurs repeatedly and less than $0,5 \%$ of the products disappear or are discarded. Case $8 \mathrm{G}$ only mentions that components of the water purifiers can be recycled and reused and case 10G states that the air separation equipment is disposed and recycled at the end of its life cycle. In case $11 \mathrm{G}$, products that have reached the EoL are disassembled and recycled by a specialized subsidiary company. 


\subsection{Specific EoL strategies for medical equipment}

Kane et al. (2017) introduces the concept of "hygienic obsolescence", characterized by medical products that no longer meet the hygienic standards. They are contaminated and can have neither new use cycles nor be recovered if not decontaminated. Thus, the medical EoL scenario is wider than the usual, since there is a new category of obsolescence that demands specific EoL treatments.

Case 6MF testifies this statement, since the use of the glucometer involves handling of blood. Thus, the device is designed for personal use due to safety issues, in a way that it can be provided only one use cycle for glucometers. The authors state that, in order to verify the feasibility of enabling new use cycles with other users, further studies must be taken, which will determine if the costs of sterilization are worth it for the advantages of looping this product. Besides the costs of decontamination processes, Kane et al. (2017) present other issue related to this EoL treatment: whether the product integrity is affected by decontamination or disinfection, which is not always easily detected.

\section{CONCLUSION}

This study has analysed eleven PSS cases of various market fields and six PSS cases applied to the medical devices industry specifically, aiming at understanding how these cases adopted the five main EoL strategies in order to promote circularity, namely repair, reconditioning, remanufacture, upgrade and recycling. The analysis allowed the authors to conclude that:

- EoL strategies are applied in different products that integrate PSS offers of various industry fields, including the medical field, and of the three PSS types, product, use and result oriented.

- None of the medical equipment PSS cases presented remanufacture and recycling as options for the EoL of the products, even though these strategies are mature in other fields of industry. The absence of medical cases mentioning remanufacture might be caused by the nomenclature problematics, once the EU denominate as 'refurbishment' the process that this paper considered as 'remanufacture', according to the american nomenclature described in CRR (2018).

- EoL implementation in the medical field demands special care, once it brings a new trigger for obsolescence and, hence, demands specific treatments to revert it. Processes of decontamination and sterilization are essential for maintaining safety and hygienic standards and meet the rigorous regulamentations, either to promoting new use cycles or to recycling the materials for new uses. This study has analysed one real case, found through the Systematic Review approach, that testifies statements made by Kane et al. (2017).

- Despite the fact that EoL strategies were found to be applied in the PSS cases of the medical field, it was possible to verify that facilitated sales are also very popular and sometimes preferred over recovering products or recycling materials. Through the lenses of circularity, this is worrisome, once the incentive for enabling new use cycles and extending lifetime of products is lost and not necessarily this asset will have an appropriate treatment when it reaches EoL, becoming waste.

- This study has considered upgrade as a EoL strategy and analysed its adoption in both espheres, general and medical. Upgrade was usually not included in this type of research, specially concerning medical devices. However, upgrade enables work life to be lengthened and is an option that should be better explored.

The importance of studies related to the End-of-Life of medical products is deeply justified by the alarming amount of waste generated by this field nowadays, which is aggravated by the field growth forecast. In pursuance of reducing the environmental damage caused by this waste, further studies are demanded in this subject. Circularity is particularly challenging in medical devices because of the potential contamination risks and this is another reason why research is essential to guide the implementation in the industry. One limitation of this study concerns the focused field. The results obtained regard the comparison between available PSS cases from diverse fields and those from the medical field. Therefore, any generalization must be made carefully.

\section{ACKNOWLEDGEMENTS}

The authors would like to thank the São Paulo Research Foundation (FAPESP) and the Higher Education Personnel Improvement Coordination (CAPES) for supporting this research. This work was supported by FAPESP under the processes 2017/24718-9 and 2017/06144-5. The opinions, hypotheses, conclusions or recommendations expressed in this paper are responsibility of the authors and do not necessarily reflect the perspective of FAPESP. 


\section{REFERENCES}

Adeogun, O., Tiwari, A. and Alcock, J. R. (2010), “Informatics-based product-service systems for point-of-care devices”, CIRP Journal of Manufacturing Science and Technology, Vol. 3 No. 2, pp. 107-115. https://doi.org/10.1016/j.cirpj.2010.04.006

Allais, R. and Gobert, J. (2016), “A multidisciplinary method for sustainability assessment of PSS: Challenges and developments”, CIRP journal of manufacturing science and technology, Vol. 15, pp. 56-64. https://doi.org/10.1016/j.cirpj.2016.04.007

Amaya, J., Lelah, A. and Zwolinski, P. (2014), "Design for intensified use in product-service systems using lifecycle analysis”, Journal of Engineering Design, Vol. 25 No. 7-9, pp. 280-302. https://doi.org/10.1080/09544828.2014.974523

Baines, T. S., Lightfoot, H. W., Evans, S., Neely, A., Greenough, R., Peppard, J. and Alcock, J. R. (2007), "State-of-the-art in product-service systems", Proceedings of the Institution of Mechanical Engineers, Part B: journal of engineering manufacture, Vol. 221 No. 10, pp. 1543-1552. https://doi.org/10.1243/09544054JEM858

Blomsma, F. and Brennan, G. (2017), "The emergence of circular economy: A new framing around prolonging resource productivity”, Journal of Industrial Ecology, Vol. 21 No. 3, pp. 603-614. https://doi.org/10.1111/jiec.12603

Bocken, N. M., de Pauw, I., Bakker, C. and van der Grinten, B. (2016), "Product design and business model strategies for a circular economy", Journal of Industrial and Production Engineering, Vol. 33 No. 5, pp. 308-320. https://doi.org/10.1080/21681015.2016.1172124

Burns, B. (2016), "Re-evaluating obsolescence and planning for it", in Cooper, E (ed.). Longer Lasting Products. Routledge, London, pp. 65-86.

Centre for Remanufacturing and Reuse (CRR). Remanufacture of medical imaging devices. Available at http://www.remanufacturing.org.uk/pdf/story/1p89.pdf. Accessed December 1st, 20019.

Chun, Y. Y. and Lee, K. M. (2017), "Environmental impacts of the rental business model compared to the conventional business model: a Korean case of water purifier for home use", The International Journal of Life Cycle Assessment, Vol. 22 No. 7, pp. 1096-1108. https://doi.org/10.1007/s11367-016-1227-1

den Hollander, M. C., Bakker, C. A. and Hultink, E. J. (2017), "Product design in a circular economy: Development of a typology of key concepts and terms", Journal of Industrial Ecology, Vol. 21 No. 3, pp. 517-525. https://doi.org/10.1111/jiec.12610

EMF (Ellen MacArthur Foundation) (2015), "Towards a circular economy-Business rationale for an accelerated transition.

Fargnoli, M., Costantino, F., Di Gravio, G. and Tronci, M. (2018), "Product service-systems implementation: A customized framework to enhance sustainability and customer satisfaction", Journal of Cleaner Production, Vol. 188, pp. 387-401. https://doi.org/10.1016/j.jclepro.2018.03.315

Goedkoop, M. (Eds.) (1999), "Product service systems, Ecological and economic basis.

Kane, G. M., Bakker, C. A. and Balkenende, A. R. (2018), "Towards design strategies for circular medical products", Resources, Conservation and Recycling, Vol. 135, pp. 38-47. https://doi.org/10.1016/j.resconrec.2017.07.030

King, A. M., Burgess, S. C., Ijomah, W. and McMahon, C. A. (2006), "Reducing waste: repair, recondition, remanufacture or recycle?", Sustainable development, Vol. 14 No. 4, pp. 257-267. https://doi.org/10.1002/sd.271

Landolfi, G., Alge, M., Bettoni, A., Canetta, L., Pedrazzoli, P. and Corti, D. (2014), "Platform architecture empowering health and safe Product Service Systems for specific target groups", Procedia CIRP, Vol. 21, pp. 117-122. https://doi.org/10.1016/j.procir.2014.03.187

Lay, G. and Schröter, M. (2014), "Manufacturers of Medical Technology: Servitization in Regulated Markets" in Lay, G. (Ed.) Servitization in industry. Springer, London, pp. 165-176

Lindahl, M., Sundin, E. and Sakao, T. (2014), "Environmental and economic benefits of Integrated Product Service Offerings quantified with real business cases", Journal of cleaner production, Vol. 64, pp. 288296. https://doi.org/10.1016/j.jclepro.2013.07.047

Liu, Q., Li, H. M., Zuo, X. L., Zhang, F. F. and Wang, L. (2009), “A survey and analysis on public awareness and performance for promoting circular economy in China: A case study from Tianjin", Journal of Cleaner Production, Vol. 17 No. 2, pp. 265-270. https://doi.org/10.1016/j.jclepro.2008.06.003

Minoglou, M., Gerassimidou, S. and Komilis, D. (2017), "Healthcare waste generation worldwide and its dependence on socio-economic and environmental factors", Sustainability, Vol. 9 No. 2, pp. 220. https://doi.org/10.3390/su9020220

Mont, O., Dalhammar, C. and Jacobsson, N. (2006), “A new business model for baby prams based on leasing and product remanufacturing”, Journal of Cleaner Production, Vol. 14 No. 17, pp. 1509-1518. https://doi.org/10.1016/j.jclepro.2006.01.024 
Pádua Pieroni, M., Blomsma, F., McAloone, T. C. and Pigosso, D. C. (2018), "Enabling circular strategies with different types of product/service-systems", Procedia CIRP, Vol. 73, pp. 179-184. https://doi.org/10.1016/j.procir.2018.03.327

Shokohyar, S., Mansour, S. and Karimi, B. (2014), “A model for integrating services and product EOL management in sustainable product service system (S-PSS)", Journal of Intelligent Manufacturing, Vol. 25 No. 3, pp. 427-440. https://doi.org/10.1007/s10845-012-0694-x

Song, W. and Sakao, T. (2018), “An environmentally conscious PSS recommendation method based on users' vague ratings: A rough multi-criteria approach”, Journal of Cleaner Production, Vol. 172, pp. 1592-1606. https://doi.org/10.1016/j.jclepro.2017.10.092

Sousa-Zomer, T. T. and Miguel, P. A. C. (2018), "Sustainable business models as an innovation strategy in the water sector: An empirical investigation of a sustainable product-service system", Journal of Cleaner Production, Vol. 171, pp. S119-S129. https://doi.org/10.1016/j.jclepro.2016.07.063

Sousa-Zomer, T. T., Magalhães, L., Zancul, E. and Cauchick-Miguel, P. A. (2018), "Exploring the challenges for circular business implementation in manufacturing companies: An empirical investigation of a pay-peruse service provider", Resources, Conservation and Recycling, Vol. 135, pp. 3-13. https://doi.org/10.1016/j.resconrec.2017.10.033

Stahel, W.R. (Eds.) (2010), “The Performance Economy. 2nd edition. Palgrave Macmillan, London.

Sundin, E. and Lee, H. M. (2012), “In what way is remanufacturing good for the environment?", In design for innovative value towards a sustainable society. Springer, Dordrecht. (pp. 552-557) https://doi.org/10.1007/978-94-007-3010-6_106

Tranfield, D., Denyer, D. and Smart, P. (2003), “Towards a methodology for developing evidence-informed management knowledge by means of systematic review", British journal of management, Vol. 14 No. 3 , pp. 207-222. https://doi.org/10.1111/1467-8551.00375

Tukker, A. (2015), "Product services for a resource-efficient and circular economy-a review", Journal of cleaner production, Vol. 97, pp. 76-91. https://doi.org/10.1016/j.jclepro.2013.11.049

Tukker, A. and Tischner, U. (2006), "Product-services as a research field: past, present and future. Reflections from a decade of research", Journal of cleaner production, Vol. 14 No. 17, pp. 1552-1556. https://doi.org/10.1016/j.jclepro.2006.01.022

Wuest, T. and Wellsandt, S. (2016), "Design and Development of Product Service Systems (PSS)-Impact on Product Lifecycle Perspective", Procedia Technology, Vol. 26, pp. 152-161. https://doi.org/10.1016/j.protcy.2016.08.021

Xing, K., Wang, H. F. and Qian, W. (2013), “A sustainability-oriented multi-dimensional value assessment model for product-service development”, International Journal of Production Research, Vol. 51 No. 19, pp. 5908-5933. https://doi.org/10.1080/00207543.2013.810349

Yip, M. H., Phaal, R. and Probert, D. R. (2014, July), "Characterizing product-service systems in the healthcare industry”, In Management of Engineering \& Technology (PICMET), 2014 Portland International Conference on (pp. 3450-3464). IEEE.

Zhang, W., Guo, J., Gu, F. and Gu, X. (2018), "Coupling life cycle assessment and life cycle costing as an evaluation tool for developing product service system of high energy-consuming equipment", Journal of Cleaner Production, Vol. 183, pp. 1043-1053. https://doi.org/10.1016/j.jclepro.2018.02.146 